其中 $\left\{E_{\mathrm{A}}\right\}$ 为 $A_{\mathrm{P}}$ 的谱系. 则

$$
\begin{gathered}
\left\{\begin{array}{c}
P_{(-\infty, \lambda]}\left(G, A_{P}\right)=-\left[\left(\lambda_{0}-A_{P}\right)^{-1} E_{\lambda} G^{*}\right]^{*}, \\
\lambda<\lambda_{0}, \\
Q_{(-\infty, \lambda]}\left(G, A_{P}\right)+Q_{\lambda_{0}}=\left[\left(\lambda_{0}\right.\right. \\
\left.\left.-A_{P}\right)^{-1} E_{\lambda} G^{*}\right]^{*} \cdot\left[\left(\lambda_{0}-A_{P}\right)^{-1} E_{\lambda} G^{*}\right],
\end{array}\right. \\
\left\{\begin{array}{c}
P_{(-\infty, \lambda]}\left(G, A_{P}\right)=\left[\left(\lambda_{0}-A_{P}\right)^{-1}(1\right. \\
\left.\left.-E_{\lambda}\right) G^{*}\right]^{*}, \lambda>\lambda_{0}, \\
Q_{(-\infty, \lambda]}\left(G, A_{P}\right)+Q_{\lambda_{0}}=-\left[\left(\lambda_{0}-A_{P}\right)^{-1}(1\right. \\
\left.\left.\left.-E_{2}\right) G^{*}\right]^{*} \cdot\left(\lambda_{0}-A_{P}\right)^{-1}\left(1-E_{\lambda}\right) G^{*}\right] .
\end{array}\right.
\end{gathered}
$$

定理 2 设 $A \in L\left(\Pi_{1}\right)$ 如 (1) 式所 示, $A$ 为循环算子, 设 $\{E(\cdot)\}$ 为 $A_{\mathrm{P}}$ 的谱 测度, $M$ 为 $\Pi_{1}$ 的闭子空间. 则 $M$ 为 $A$ 的不 变子空间当且仅当 $M$ 满足以下条件之一:

(i) $M=Z \oplus N$. 其中 $N \subseteq P, N \in$
Lat $A_{P}$;

(ii) 存在 $\sigma(A)$ 的 Borel 子集 $\sigma$, 使得 $M=R(B)$, 其中 $B=\{\alpha, E(\sigma), U, V\}$ 为 与 $A$ 可交换的投影算子. 进而当 $\left(\lambda_{0}-A_{P}\right)^{-1}$ $E(\sigma) G^{*} z^{*} \in P$, 则 $\alpha=0$. $U^{*}=-\left[\left(\lambda_{0}-\right.\right.$ $\left.\left.A_{P}\right)^{-1} E(\sigma) G^{*}\right], V=U U^{*}$. 当 $\left(\lambda_{0}-A_{P}\right)^{-1}$ $(1-E(\sigma)) G^{*} z^{*} \in P$, 则 $\alpha-1, U^{*}=$ $\left[\left(\lambda_{0}-A_{P}\right)^{-1}(1-E(\sigma)) G^{*}\right], V=-U U^{*}$.

\section{至支献}

[1]而道行、严绍宗, 线性算子垪理论 II, 不定度规空 间上算子理论,科学出版社, 北京, 1987 .

陈 铭

(激江师范大学数学系, 金华 321004)

\title{
球面上的 Ahlfors 基本定理*
}

设 $V$ 是一个半径为 1 的单位 Riemann 球面, $F_{0}$ 是球面 $V$ 上的一个区域, $F$ 是 $F_{0}$ 的 有限覆盖曲面. 令

$$
S=\frac{|\underline{F}|}{\left|\underline{F_{0}}\right|},
$$

其中 $|F|,\left|F_{0}\right|$ 分别表示 $F, F_{0}$ 的面积. 我 们称 $S$ 为 $F_{0}$ 的平均覆盖次数. 令 $L$ 为 $F$ 的 租对边界长, 即 $F$ 的边界中, 那些落在 $F_{0}$ 内 部的部分的长.

Ahlfors 篮曲面基本定理 设 $F_{0}$ 是单位球面 $V$ 上的一个区域, 它的边界是 $q$
个不同的点, 其中任意二点间的球面距离不 小于 $d \in(0,0.5 \pi)$, 则对任何连通的有限覆 盖曲面 $F$, 有

$$
\rho^{+}(F) \geqslant \rho\left(F_{0}\right) S-h(d) L,
$$

其中 $\rho(F)$ 表示 $F$ 的 Euler 特征数; $\rho^{+}=$ $\max (0, \rho) ; h(d)$ 是一个仅与 $d$ 有关的常数. 比如, 它可以为

$$
\begin{array}{r}
h(d)=2^{25} \pi^{19} d^{-19} . \\
\text { 孙道椿 }
\end{array}
$$

(武汉.大学数学系, 武汉 430072)

\footnotetext{
* 国家自然科学基金资助项目.
}

\section{掺镁铌酸锂晶体的 $\mathrm{OH}^{-}$偏振红外吸收谱*}

按照我们提出的掺镁 $\mathrm{LiNbO}_{3}$ 晶体间 值效应模型, 对一致熔化组分晶体, 间值掺镁 浓度应为 $5.3 \mathrm{~mol} \%$ 出. 最近, 我们测量了掺 镁 $\mathrm{LiNbO}_{3}$ 中 $\mathrm{OH}^{-}$红外吸收带的偏振性 质, 其结果再次验证了上述模型.
选取 $\mathrm{MgO}$ 含量分别为 $5.0,6.0$ 和 9.0 $\mathrm{mol} \%$ 的三个样品(记作 M 5.0, M 6.0 和 M 9.0). 样品的室温偏振红外吸收谱系采用

*国家自然科学基金资助项目. 